УДК 622.06

\title{
РАЗРАБОТКА ТЕХНОЛОГИЧЕСКОГО КОМПЛЕКСА ПО ПЕРЕРАБОТКЕ НИЗКОСОРТНЫХ И ОКИСЛЕННЫХ УГЛЕЙ НА МЕСТЕ ДОБЫЧИ
}

Сентюрев С.A.

Амлин М.С. студенты

Научный руководитель: Мурко Василий Иванович д.т.н., профессор ФГБОУ ВО «Сибирский государственный индустриальный университет»

Аннотация: на основании проведенных экспериментальных исследований предлагается технология по переработке низкосортных и окисленных углей на месте добычи. Основой технологического процесса является процесс газификации твердого топлива, осуществляемый в разработанном образце газификатора. В работе представлены результаты экспериментальных исследований процесса подготовки твердого топлива для полной газификации. Проанализированы возможные варианты использования получаемого генераторного газа в качестве топлива при выработке электрической энергии.

Ключевые слова: переработка низкосортных и окисленных углей, газификация твердого топлива, выработка электрической энергии.

\section{DEVELOPMENT OF A TECHNOLOGICAL COMPLEX FOR PROCESSING LOW-GRADE AND OXIDIZED CARBONS AT THE MINING PLACE}

Sentyurev S.A. Amlin M.S. Scientific adviser: Murko Vasiliy Ivanovich

Abstract: on the basis of the conducted experimental studies, a technology is proposed for processing low-grade and oxidized coals at the mining site. The basis of the technological process is the process of gasification of solid fuel, carried out in 
the developed sample of the gasifier. The paper presents the results of experimental studies of the process of preparing solid fuel for complete gasification. Possible options for using the produced generator gas as a fuel in the generation of electrical energy have been analyzed.

Key words: processing of low-grade and oxidized coals, gasification of solid fuels, generation of electrical energy.

\section{Состояние вопроса.}

Кузбасс (Кузнецкий угольный бассейн) является одним из крупных месторождений угля в мире. В Кемеровской области добывается около 60\% российского угля и более $80 \%$ наиболее ценных коксующихся марок [1].

По данным из источника «Администрации Правительства Кузбасса» в 2019 году угольщики Кузбасса добыли 250,1 млн тонн каменного угля (2018 год - 255,3 млн тонн). На угольных разрезах добыто 164,4 млн тонн (2018 год $-165,8$ млн тонн), в шахтах $-85,7$ млн тонн угля (2018 год $-89,5$ млн тонн).

Большинство полезных ископаемых, которые в силу специфики геологического развития блока земной коры, вмещающего их, оказываются в его верхних частях на контакте с внешними геосферами Земли (атмо-, гидрои биосферой), испытывают значительные трансформации физических свойств и химического состава. Эти изменения обусловлены экзогенными геологическими процессами, в частности, физическим и химическим выветриванием. Угольные месторождения - не исключение, они также подвержены физическому и химическому выветриванию. Одним из составных частей последнего является окисление, вызванное наличием кислорода в атмосфере, поверхностных водах и подземных водах зоны аэрации.

Интенсивность окислительного выветривания и глубина его проникновения определяются климатом, скоростью эрозионных процессов, условиями залегания угольных пластов, уровнем грунтовых вод и его постоянством, а также петрографическими особенностями угля [2].

В настоящее время актуальной является проблема использования малокалорийного окисленного угля, из-за низких качественных свойств уголь не востребован на рынке и его либо отправляют на длительное хранение на угольный склад, либо увозят в отвал. В результате долгого хранения и воздействия химических процессов, углю свойственно самовозгорание, что приводит к пожарам и выделению значительных вредных выбросов в атмосферу. 
Аналогичные проблемы возникают при использовании бурых углей. Ввиду их малой калорийности и склонностью к самовозгоранию использование данных углей ограничено потребителями с близлежащей территории. Таким образом, для повышения эффективности работы угольных предприятий, в первую очередь, добывающих уголь открытым способом и бурый уголь, стоит проблема использования низкосортных и малокалорийных углей на месте их добычи. Помимо экономической эффективности для добывающих предприятий в местах их расположения существенно снизится нагрузка на окружающую среду.

В настоящее время разработано несколько технологических направлений для решения указанной проблемы [3 - 5].

В работе [3] предложена технология переработки угля в местах его добычи с использованием технологии газификации добываемого угля с получением конкурентно способных продуктов с высокой добавленной стоимостью в том числе: углеводородный газ и жидкие смолистые вещества, а так же твердый остаток (шлак) после газификации.

Наибольшее распространение в России получила технология пиролиза бурых углей и каменных (с выходом летучих веществ) углей «Термококс» [4]. Данная технология относится к новому поколению безотходных, экологически безопасных технологий энерготехнологической переработке угля, которое имеет повышенный уровень энергоэффективности.

Суть её состоит в том, что уголь газифицируется в стационарных газификаторах слоевого типа с получением среднетемпературного полукокса (термококса) и генераторного газа энергетического назначения, не содержащего угольной смолы, газ сжигается на месте в бойлере для производства тепловой энергии или газификационной машине с производством тепла и электрической энергии, а термококс является сырьем для производства различной продукции: бездымное бытовое топливо, углеродные сорбенты, заменитель металлургического кокса и т.П. Параллельное производство двух ценных продуктов радикальным образом изменяет экономические показатели комплексного производства, что ведет к существенному снижению сроков окупаемости инвестиций.

Перспективным направлением использования низкосортных и малокалорийных углей является создание угольных мини-ТЭЦ, мощность которых составляет от нескольких киловатт до 25 МВт, при этом объектами энергоснабжения могут быть близлежащие промышленные предприятия, 
предприятия коммунального хозяйства, а так же собственное потребление и др. на рисунке 1 представлены технологические схемы угольных мини-ТЭЦ [5].

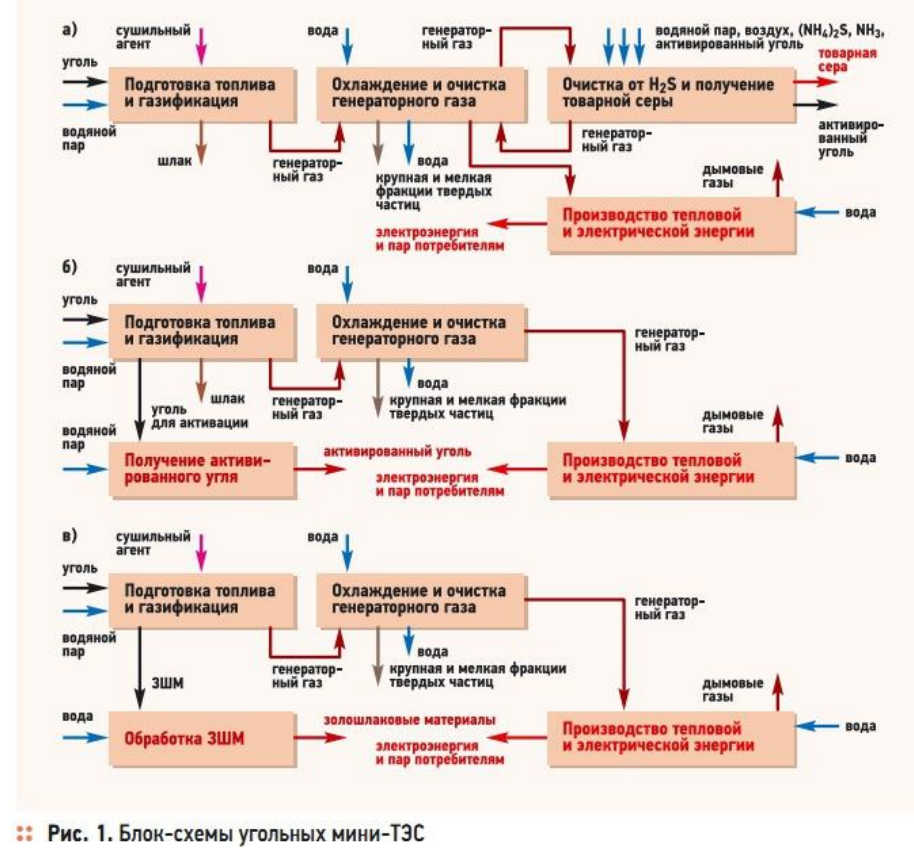

Рис. 1. Блок-схемы угольных мини-ТЭЦ

\section{Предлагаемый технологический комплекс.}

Нами предлагается технологический комплекс по использованию низкокалорийных или окисленных углей, добываемых открытым способом в непосредственной близости от разреза, а именно на «нерабочем» борту разреза.

Схема предлагаемой технологии представлена на рисунке 2.

Суть предлагаемой технологии:

Исходное сырье подается на комплекс дробления и сортировки, с получением класса 0.5-25 мм. Полученный продукт направляется на газификацию в газогенераторную установку непрерывного действия. В газогенераторной установке производится газогенераторный газ, который после очистки отправляется на: паротурбинную, газопоршневую или газотурбинную установку. Зольный остаток газогенераторной установки удаляется на породный отвал. 


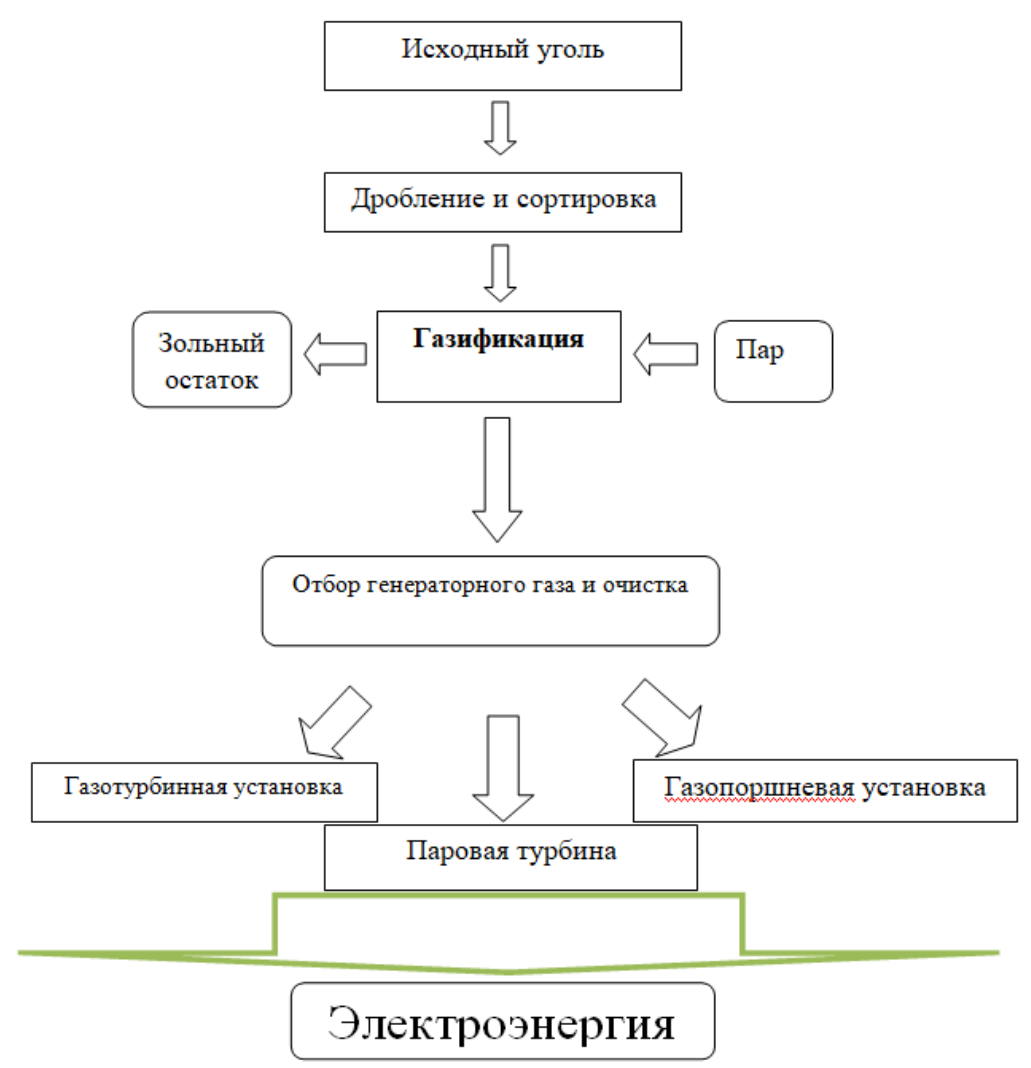

\section{Рис. 2. Технология использования низкокалорийных или окисленных углей}

Преимущество предлагаемой технологии:

- использование низкокалорийных и окисленных углей по их прямому назначению;

- минимальные затраты на транспортировку;

- снижение технологических потерь угля при их добыче;

- получение электроэнергии и тепловой (при необходимости) энергии;

- снижение экологической нагрузки в месте добычи угля.

Одним из основных элементов технологического комплекса является газогенераторная установка непрерывного действия, в которой производится воздушная или паровоздушная газификация твердого топлива с получением генераторного газа и твердого остатка (полукокса, угольного сорбента или шлака). Газогенератор разработан и введен в эксплуатацию ООО НПЦ «Сибэкотехника», СибГИУ при творческом содействии и материальной помощи Ю.С. Щапова.

На рисунке 3 представлена конструкция предлагаемого газогенератора. 


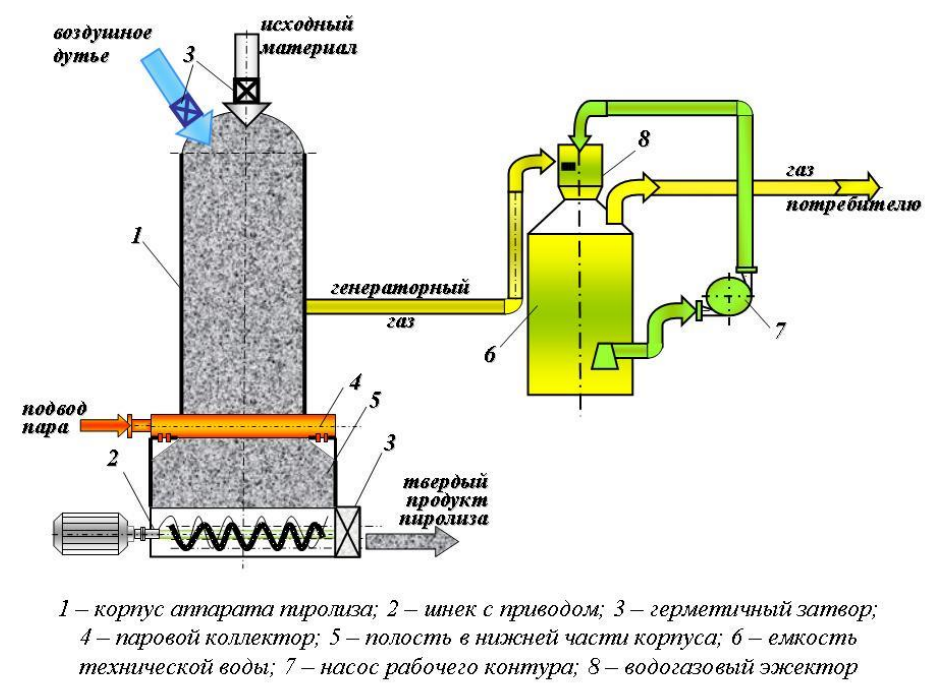

\section{Рис. 3. Схема газогенератора непрерывного действия}

Преимуществами предложенного газогенератора являются:

- осуществление процесса получения генераторного газа в непрерывном режиме;

- использование водогазового эжектора для удаления генераторного газа из зоны газификации;

- равномерный подвод пара в зону газификации.

Использование водогазового эжектора позволяет не только отбирать генераторный газ, но и концентрировать водосмоляную жидкость с дальнейшим направлением ее на очистку или переработку.

Конструкция генераторной установки непрерывного действия патентуется.

\section{Экспериментальная часть.}

Для подтверждения основных технологических решений предлагаемого технологического комплекса были проведены экспериментальные работы на демонстрационном стенде СибГИУ [6].

Для исследований использовались угли разрезов «Чулым-уголь», Хакасия (бурый уголь марки Б2) и «Задубровский», Кузбасс (каменный уголь марки Д). Крупность угля предварительно отобранных проб марки Б2 составляла 0-250 мм, а угля марки Д 0-300 мм. Отбор проб угля, определение гранулометрического состава, зольности и влажности определялся по ГОСТам: 10742-71, 33814-2016.

Указанные пробы угля были раздроблены в молотковой дробилке. После дробления верхняя крупность угля снизилась до 25 мм. Дробленый 
уголь был подвергнут ситовому анализу с определением зольности и влажности каждого класса крупности.

В таблицах 1, 2 представлены результаты ситового анализа и определения зольности.

Из результатов таблиц видно, что распределение зольности в классах бурого угля неравномерное: классы 13-25 мм, 6-13 мм, обладают повышенной зольностью, в сравнении с классом 3-6 мм, 0-3 мм. У каменного угля наоборот, мелкие классы обладают повышенной зольностью, в отличие от более крупных.

Результаты гранулометрического состава дробленых проб углей были обработаны с использованием аналитической зависимости в виде уравнения Розина - Раммлера [7].

$$
R=100 e^{-b d^{n}}
$$

где R - суммарный выход класса крупнее d ( по “+” ), \%;

$\mathrm{d}$ - размер отверстий сита;

b и n - коэффициенты, зависящие от свойств материала.

Значения коэффициентов для гранулометрических составов бурого и каменного углей (табл. 1 и 2) были определены с использованием метода наименьших квадратов [8].

На рисунках 4, 5 представлены результаты расчетов и графики полученных кривых гранулометрического состава.

Как видно, из полученных результатов формула Розина - Раммлера с высокой точностью описывает результаты гранулометрического состава проб дробленых бурого и каменного углей (отклонение аналитических значений от экспериментальных данных составляет соответственно: 1,27 и 0,42).

Таблица 1

\section{Гранулометрический состав и зольность бурого угля}

\begin{tabular}{|c|c|c|c|c|}
\hline \multirow{3}{*}{$\begin{array}{c}\text { Классы } \\
\text { крупности, мм. }\end{array}$} & \multicolumn{4}{|c|}{ Показатели } \\
\hline & \multicolumn{3}{|c|}{ выход, \% } & \multirow{2}{*}{$\begin{array}{c}\text { зольность по } \\
\text { классам, \% }\end{array}$} \\
\hline & по классам & сверху & снизу & \\
\hline $13,0-25,0$ & 14,8 & 14,8 & 100,0 & 8,5 \\
\hline $6,0-13,0$ & 29,9 & 44,7 & 85,2 & 8,4 \\
\hline $3,0-6,0$ & 23,1 & 67,8 & 55,3 & 7,3 \\
\hline $1,0-3,0$ & 16,4 & 84,2 & 32,2 & 9,3 \\
\hline $0,5-1,0$ & 6,2 & 90,4 & 15,8 & 9,7 \\
\hline $0-0,5$ & 9,6 & 100,0 & 9,6 & 11,2 \\
\hline Итого & 100,0 & & & 8,7 \\
\hline
\end{tabular}


Таблица 2

Гранулометрический состав и зольность каменного угля

\begin{tabular}{|c|c|c|c|c|}
\hline \multirow{3}{*}{$\begin{array}{c}\text { Классы } \\
\text { крупности, мм. }\end{array}$} & \multicolumn{4}{|c|}{ Показатели } \\
\hline & \multicolumn{3}{|c|}{ Выход, \% } & \multirow{2}{*}{$\begin{array}{c}\text { зольность по } \\
\text { классам, \% }\end{array}$} \\
\hline & по классам & сверху & снизу & \\
\hline $13,0-25,0$ & 16,3 & 16,3 & 100 & 6,9 \\
\hline $6,0-13,0$ & 21,4 & 37,7 & 83,7 & 7,7 \\
\hline $3,0-6,0$ & 19,3 & 57 & 62,7 & 7,9 \\
\hline $1,0-3,0$ & 15,5 & 72,5 & 43 & 11,0 \\
\hline $0,5-1,0$ & 11,3 & 83,8 & 27,7 & 15,4 \\
\hline $0-0,5$ & 16,2 & 100,0 & 16,2 & 16,3 \\
\hline Итого & 100,0 & & & 10,4 \\
\hline
\end{tabular}

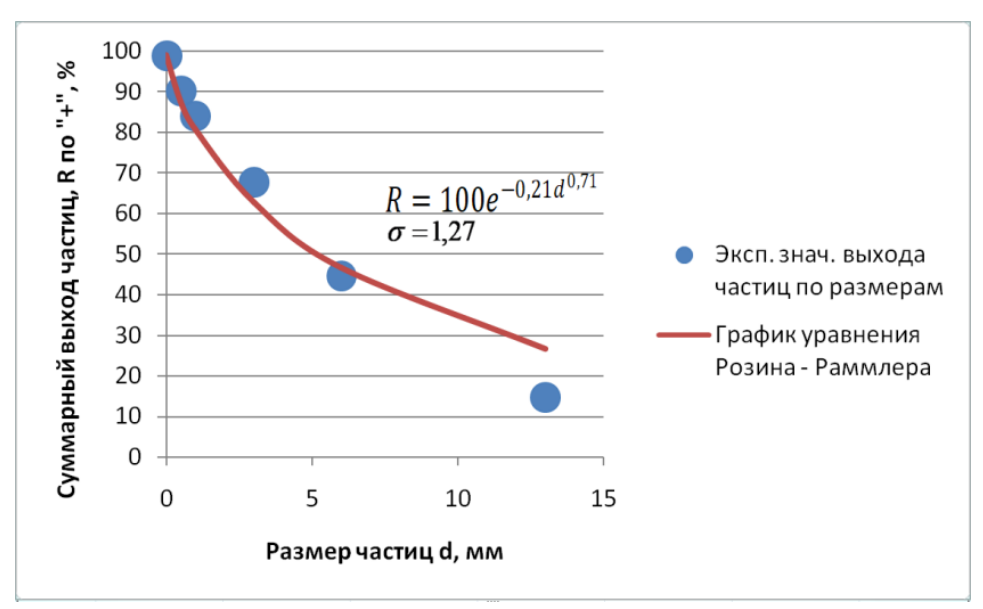

Рис. 4. График кривой гранулометрического состава дробленого бурого угля

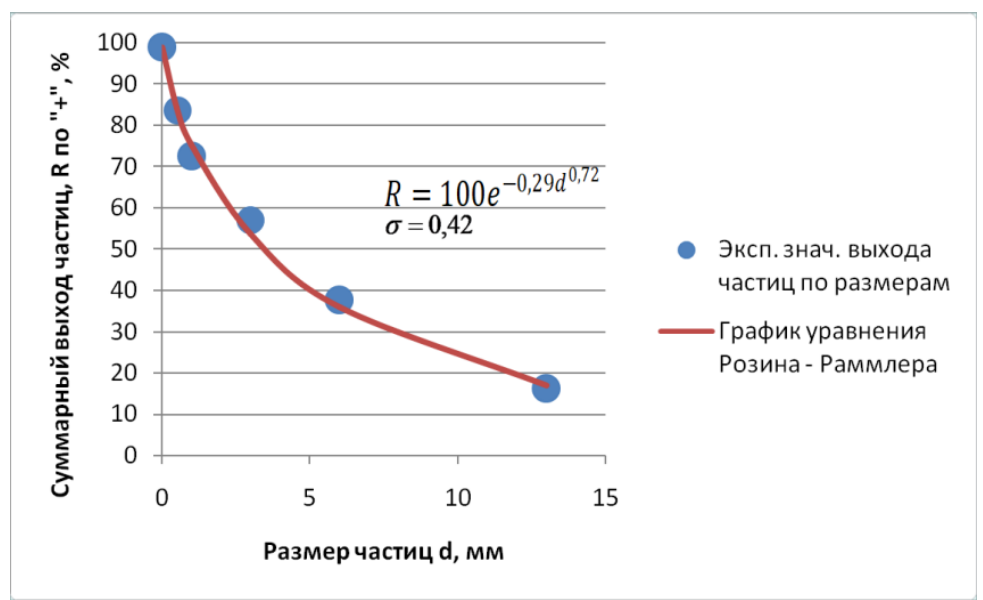

Рис. 5. График кривой гранулометрического состава дробленого каменного угля 
Газификации на экспериментальном образце аппарата (рисунок 6) подвергался уголь классов 3-6 мм и 6-13 мм.

В таблице 3 представлены первые результаты экспериментов по газификации проб углей.

Таблица 3

Характеристика продуктов газификации

\begin{tabular}{|c|c|c|c|c|c|}
\hline \multirow{3}{*}{$\begin{array}{l}\text { № } \\
\text { II/II }\end{array}$} & \multirow{3}{*}{ Наименование параметра } & \multicolumn{4}{|c|}{ Наименование продукта } \\
\hline & & \multicolumn{2}{|c|}{ Твердый продукт } & \multicolumn{2}{|c|}{ Газообразный продукт } \\
\hline & & марка «Б» & марка «Д» & марка «Б» & марка «Д» \\
\hline 1. & Влажность, \% & $4,6 / 33,2 *$ & $5,6 / 6,5^{*}$ & & \\
\hline 2. & Зольность, \% & $13,7 / 7,6^{*}$ & $15,3 / 10,4^{*}$ & & \\
\hline 3. & $\begin{array}{l}\text { Выход летучих на сухое беззольное } \\
\text { состояние, } \mathrm{V}^{\text {daf }}, \%\end{array}$ & $14,1 / 48,1^{*}$ & нет данных & & \\
\hline 4. & Низшая теплота сгорания, МДж/кг & $21,5 / 14,3^{*}$ & $26,7 / 27,9 *$ & $2,5 / 5,9 * *$ & 3,0 \\
\hline 5. & Содержание газов, об. \%: & & & & \\
\hline 6. & метан, $\mathrm{CH}_{4}$ & & & $1,56 / 1,4 * *$ & 4,04 \\
\hline 7. & диоксид углерода, $\mathrm{CO}_{4}$ & & & $19,56 / 9,12 * *$ & 13,67 \\
\hline 8. & водород, $\mathrm{H}_{2}$ & & & $15,1 / 13,59^{* *}$ & 13,76 \\
\hline 9. & кислород, $\mathrm{O}_{2}$ & & & $0,65 / 2,96^{* *}$ & 0,94 \\
\hline 10. & азот, $\mathrm{N}_{2}$ & & & $52,25 / 53,0^{* *}$ & 60,42 \\
\hline 11. & окись углерода, СО & & & $5,68 / 19,75 * *$ & 6,37 \\
\hline
\end{tabular}

* исходный уголь

** при паровоздушной газификации.

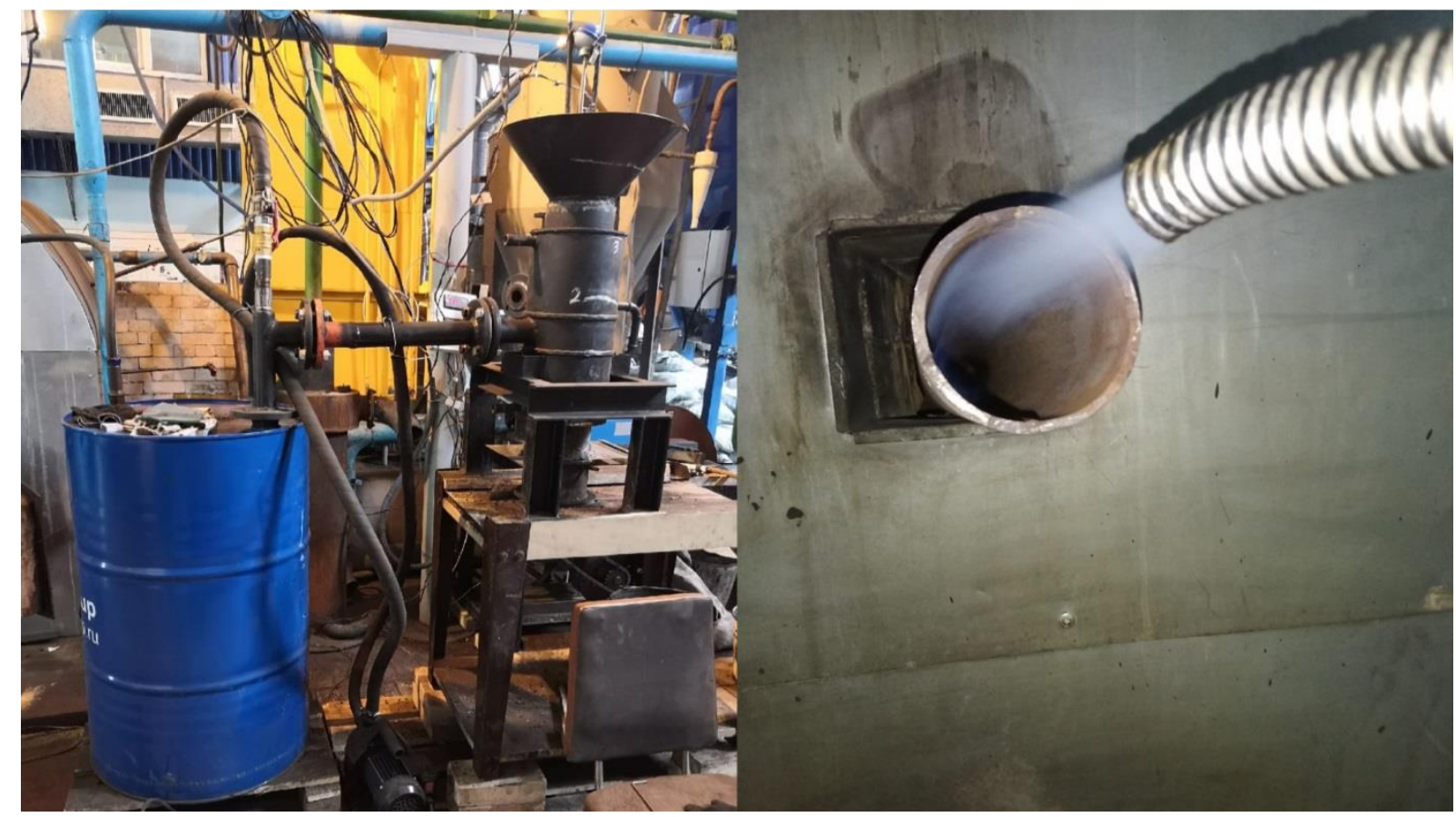

Рис. 6. Общий вид газогенераторной установки и выход генераторного газа 
Полученный генераторный газ может отправляться либо на:

- сжигание в паровой котел с последующим направлением пара на паровой турбогенератор;

- газотурбинную установку;

- газопоршневую установку.

Выбор способа получения электроэнергии производится на стадии получения технического задания, разработки технико-экономического обоснования и последующего проектирования.

Полученные результаты подтверждают возможность как частичной (воздушной), так и полной газификации бурых и каменных углей с получением генераторного газа и твердого остатка (полукокса, угольного сорбента или шлака).

\section{Заключение.}

Выполненные исследования показывают на техническую возможность реализации технологического комплекса по переработке низкосортных и окисленных углей на месте добычи. В результате достигается:

- использование низкокалорийных и окисленных углей по их прямому назначению;

- минимальные затраты на транспортировку;

- снижение технологических потерь угля при их добыче;

- получение электроэнергии и тепловой (при необходимости) энергии;

- снижение экологической нагрузки в месте добычи угля.

Авторы статьи выражают благодарность научному руководителю, сотрудникам СибГИУ и ООО НПЦ «Сибэкотехника» (г. Новокузнецк) за методическую и практическую помощь при проведении исследований, Ю.С. Щапову за оказание методической и материальной помощи при разработке и изготовлении образцов оборудования стенда.

\section{Список литературы}

1. В 2019 году угольщики Кузбасса добыли 250,1 миллиона тонн каменного угля | Администрация Правительства Кузбасса. - Режим доступа: https://ako.ru/news/detail/v-2019-godu-ugolshchiki-kuzbassa-dobyli-250-1millionov-tonn-kamennogo-uglya-.

2. Зоны окисления угольных месторождений » Строительный ресурс. Режим доступа: http://spb-sovtrans.ru/geologiya-tverdyh-goryuchih-iskopaemyh/ 336-zony-okisleniya-ugolnyh-mestorozhdeniy.html 
3. Астановский Д.Л., Астановский Л.3., Кустов П.В., Бурданов А.В. Переработка угля в местах его добычи по технологии «Фаст Инжиниринг». Ж. «Кокс и химия» №7, 2020, с. 8-12.

4. Степанов С.Г., Логинов Д.А., Кочетков В.Н. Термическое обогащение угля как инструмент повышения эффективности угольного бизнеса. Горный информационно-аналитический бюллетень, н. S45-2, 2015, с. 7-14.

5. Угольные мини-ТЭС с производством побочных продуктов | Архив C.O.К. | 2013 | №7. - Режим доступа:https://www.c-o-k.ru/articles/ugol-nyeminites-s-proizvodstvom-pobochnyh-produktov.

6. Мурко В.И., Протопопов Е.В., Темлянцев М.В. и др. Разработка и создание инновационного научно-образовательного кластера по комплексному использованию угля и продуктов его переработки, «Системы автоматизации в образовании, науке и производстве, AS' 2019», Труды XII Всероссийской научно-практической конференции (с международным участием), с. 48-53, г. Новокузнецк, 2012.

7. Андреев Е.Е., Тихонов О.Н. Дробление, измельчение и подготовка сырья к обогащению. Учебник, с. 440, г. Санкт-Петербург, 2007.

8. Коломиец Л.В., Поникарова Н.Ю. Метод наименьших квадратов. Учебное пособие, с. 32, Издательство Самарского университета, 2017.

() С.А. Сентюрев, М.С. Амлин 